\title{
Preface (1944 and 1947)
}

When* we began this work, the first samples of which we dedicate to Friedrich Pollock, we hoped to be able to present the whole book on his fiftieth birthday. But the further we proceeded with the task the more we became aware of the mismatch between it and our own capabilities. What we had set out to do was nothing less than to explain why humanity, instead of entering a truly human state, is sinking into a new kind of* barbarism. We underestimated the difficulty of dealing with the subject because we still placed too much trust in contemporary consciousness. While we had noted for many years that, in the operations of modern science, the major discoveries are paid for with an increasing* decline of theoretical education, we nevertheless believed that we could follow those operations to the extent of limiting our work primarily to a critique or a continuation of specialist theories. Our work was to adhere, at least thematically, to the traditional disciplines: sociology, psychology, and epistemology.

The fragments we have collected here show, however, that we had to abandon that trust. While attentive cultivation and investigation of the scientific heritage-especially when positivist new brooms have swept it away as useless lumber-does represent one moment of knowledge, in the present collapse of bourgeois civilization not only the operations but the purpose of science have become dubious. The tireless self-destruction of enlightenment hypocritically celebrated by implacable fascists and implemented by pliable experts in humanity* compels thought to forbid itself its last remaining innocence regarding the habits and tendencies of the Zeitgeist. If public life has reached a state in which thought is being turned inescapably into a commodity and language into celebration of the commodity, the attempt to trace the sources of this degradation must refuse 
obedience to the current linguistic and intellectual demands before it is rendered entirely futile by the consequence of those demands for world history.

If the only obstacles were those arising from the oblivious instrumentalization of science, thought about social questions could at least attach itself to tendencies opposed to official science. Those tendencies, too, however, are caught up in the general process of production. They have changed no less than the ideology they attacked. They suffer the fate which has always been reserved for triumphant thought. If it voluntarily leaves behind its critical element to become a mere means in the service of an existing order, it involuntarily tends to transform the positive cause it has espoused into something negative and destructive. The eighteenthcentury philosophy which, defying the funeral pyres for books and people, put the fear of death into infamy, joined forces with it under Bonaparte. Finally, the apologetic school of Comte usurped the succession to the uncompromising encyclopédistes, extending the hand of friendship* to all those whom the latter had opposed. Such metamorphoses of critique into affirmation do not leave theoretical content untouched; its truth evaporates. Today, however, motorized history is rushing ahead of such intellectual developments, and the official spokesmen, who have other concerns, are liquidating the theory to which they owe their place in the sun* before it has time to prostitute itself completely.*

In reflecting on its own guilt, therefore, thought finds itself deprived not only of the affirmative reference to science and everyday phenomena but also of the conceptual language of opposition. No terms are available which do not tend toward complicity with the prevailing intellectual trends, and what threadbare language cannot achieve on its own is precisely made good by the social machinery. The censors voluntarily maintained by the film factories to avoid greater costs have their counterparts in all other departments. The process to which a literary text is subjected, if not in the automatic foresight of its producer then through the battery of readers, publishers, adapters, and ghost writers inside and outside the editorial office, outdoes any censor in its thoroughness. To render their function entirely superfluous appears, despite all the benevolent reforms, to be the ambition of the educational system. In the belief that without strict limitation to the observation of facts and the calculation of probabilities the cognitive mind would be overreceptive to charlatanism and 
superstition, that system is preparing arid ground for the greedy acceptance of charlatanism and superstition. Just as prohibition has always ensured the admission of the poisonous product, the blocking of the theoretical imagination has paved the way for political delusion. Even when people have not already succumbed to such delusion, they are deprived by the mechanisms of censorship, both the external ones and those implanted within them, of the means of resisting it.

The aporia which faced us in our work thus proved to be the first matter we had to investigate: the self-destruction of enlightenment. We have no doubt - and herein lies our petitio principii-that freedom in society is inseparable from enlightenment thinking. We believe we have perceived with equal clarity, however, that the very concept of that thinking, no less than the concrete historical forms, the institutions of society with which it is intertwined, already contains the germ of the regression* which is taking place everywhere today. If enlightenment does not assimilate reflection on this regressive moment, it seals its own fate. By leaving consideration of the destructive side of progress to its enemies, thought in its headlong* rush into pragmatism is forfeiting its sublating character, and therefore its relation to truth. In the mysterious willingness of the technologically educated masses to fall under the spell of any despotism, in its self-destructive affinity to nationalist paranoia, in all this uncomprehended senselessness the weakness of contemporary theoretical understanding is evident.

We believe that in these fragments we have contributed to such understanding by showing that the cause of enlightenment's relapse into mythology is to be sought not so much in the nationalist, pagan, or other modern mythologies concocted specifically to cause such a relapse as in the fear of truth which petrifies enlightenment itself. Both these terms, enlightenment and truth, are to be understood as pertaining not merely to intellectual history but also to current reality. Just as enlightenment expresses the real movement of bourgeois society as a whole from the perspective of the idea embodied in its personalities and institutions, truth refers not merely to rational* consciousness but equally to the form it takes in reality. The loyal son of modern civilization's fear of departing from the facts, which even in their perception are turned into clichés by the prevailing usages in science, business, and politics, is exactly the same as the fear of social deviation. Those usages also define the concept of clarity in 
language and thought to which art, literature, and philosophy must conform today. By tabooing any thought which sets out negatively from the facts and from the prevailing modes of thought as obscure, convoluted, and preferably foreign, that concept holds mind captive in ever deeper blindness. It is in the nature of the calamitous situation existing today that even the most honorable reformer who recommends renewal in threadbare language reinforces the existing order he seeks to break by taking over its worn-out categorial apparatus and the pernicious power-philosophy lying behind it. False clarity is only another name for myth. Myth was always obscure and luminous at once. It has always been distinguished by its familiarity and its exemption from the work of concepts.

The enslavement to nature of people today cannot be separated from social progress. The increase in economic productivity which creates the conditions for a more just world also affords the technical apparatus and the social groups controlling it a disproportionate advantage over the rest of the population. The individual is entirely nullified in face of the economic powers. These powers are taking society's domination over nature to unimagined heights. While individuals as such are vanishing before the apparatus they serve, they are provided for by that apparatus and better than ever before. In the unjust state of society the powerlessness and pliability of the masses increase* with the quantity of goods allocated to them. The materially considerable and socially paltry rise in the standard of living of the lower classes is reflected in the hypocritical propagation of intellect. Intellect's true concern is a negation of reification. It must perish when it is solidified into a cultural asset and handed out for consumption purposes. The flood of precise information and brand-new amusements make people smarter and more stupid at once.

What is at issue here is not culture as a value, as understood by critics of civilization such as Huxley, Jaspers, and Ortega y Gasset, but the necessity for enlightenment to reflect on itself if humanity is not to be totally betrayed. What is at stake is not conservation of the past but the fulfillment of past hopes. Today, however,* the past is being continued as destruction of the past. If, up to the nineteenth century, respectable education was a privilege paid for by the increased sufferings* of the uneducated, in the twentieth the hygienic factory is bought with the melting down of all cultural entities in the gigantic crucible.* That might not even be so high a price as those defenders of culture believe if the bargain sale 
of culture did not contribute to converting economic achievements into their opposite.

Under the given circumstances the gifts of fortune themselves become elements of misfortune. If, in the absence of the social subject, the volume of goods took the form of so-called overproduction in domestic economic crises in the preceding period, today, thanks to the enthronement of powerful groups as that social subject, it is producing the international threat of fascism: progress is reverting to regression. That the hygienic factory and everything pertaining to it, Volkswagen* and the sports palace, are obtusely liquidating metaphysics does not matter in itself, but that these things are themselves becoming metaphysics, an ideological curtain, ${ }^{*}$ within the social whole, behind which real doom is gathering, does matter. That is the basic premise of our fragments.

The first essay, the theoretical basis of those which follow, seeks to gain greater understanding of the intertwinement of rationality and social reality, as well as of the intertwinement, inseparable from the former, of nature and the mastery of nature. The critique of enlightenment given in this section is intended to prepare a positive concept of enlightenment which liberates it from its entanglement in blind domination.

The critical part of the first essay can be broadly summed up in two theses: Myth is already enlightenment, and enlightenment reverts to mythology. These theses are worked out in relation to specific subjects in the two excurses. The first traces the dialectic of myth and enlightenment in the Odyssey, as one of the earliest representative documents of bourgeois Western civilization. It focuses primarily on the concepts of sacrifice and renunciation, through which both the difference between and the unity of mythical nature and enlightened mastery of nature become apparent. The second excursus is concerned with Kant, Sade, and Nietzsche, whose works represent the implacable consummation of enlightenment. This section shows how the subjugation of everything natural to the sovereign subject culminates in the domination of what is blindly objective and natural. This tendency levels all the antitheses of bourgeois thought, especially that between moral rigor and absolute amorality.

The section "The Culture Industry" shows the regression of enlightenment to ideology which is graphically expressed in film and radio. Here, enlightenment consists primarily in the calculation of effects and in the technology of production and dissemination; the specific content of the 
ideology is exhausted in the idolization of the existing order and of the power by which the technology is controlled. In the discussion of this contradiction the culture industry is taken more seriously than it might itself wish to be. But because its appeal to its own commercial character, its confession of its diminished truth, has long since become an excuse with which it evades responsibility for its lies, our analysis is directed at the claim objectively contained in its products to be aesthetic formations and thus representations of truth. It demonstrates* the dire state of society by the invalidity of that claim. Still more than the others, the section on the culture industry is fragmentary.*

The discussion, in the form of theses, of "Elements of AntiSemitism" deals with the reversion of enlightened civilization to barbarism in reality. The not merely theoretical but practical tendency toward selfdestruction has been inherent in rationality from the first, not only in the present phase when it is emerging nakedly. For this reason a philosophical prehistory of anti-Semitism is sketched. Its "irrationalism" derives from the nature of the dominant reason and of the world corresponding to its image. The "elements" are directly related to empirical research by the Institute of Social Research, ${ }^{*}$ the foundation set up and kept alive by Felix Weil, without which not only our studies but the good part of the theoretical work of German emigrants carried forward despite Hitler would not have been possible. We wrote the first three theses jointly with Leo Löwenthal, with whom we have collaborated on many scholarly questions since the first years in Frankfurt.

In the last section we publish notes and sketches which, in part, form part of the ideas in the preceding sections, without having found a place in them, and in part deal provisionally with problems of future work. Most of them relate to a dialectical anthropology.*

Los Angeles, California, May 1944

The book contains no essential changes to the text completed during the war. Only the last thesis of "Elements of Anti-Semitism" was added subsequently.

Max Horkheimer Theodor W. Adorno

June 1947 
This page intentionally left blank 